\title{
Pós-materialismo e participação política no Brasil
}

\author{
EdNALdo Aparecido Ribeiro \\ Doutor em Sociologia \\ Professor da UEM. \\ ednaldorip@uol.com.br
}

\begin{abstract}
Resumo Defensores da teoria do desenvolvimento humano têm afirmado que nas últimas décadas estaria ocorrendo em escala mundial um processo de mudança nas prioridades valorativas dos indivíduos em direção a uma postura pós-materialista. Um dos principais componentes dessa (re) orientação seria a aspiração por auto-expressão que, por sua vez, engendraria demandas por mecanismos que possibilitariam a participação ativa e autônoma dos cidadãos na política. No presente artigo, analisamos a validade dessa tese no contexto brasileiro, no qual a literatura pertinente tem indicado a existência de uma cultura política repleta de elementos autoritários e não muito favoráveis ao estabelecimento de práticas participativas. Tratamos, portanto, de testar a hipótese da associação entre a síndrome pós-materialista e um conjunto de valores e atitudes relacionados ao tema da participação na população nacional. Utilizando as bases de dados produzidas pelas duas pesquisas realizadas pelo Projeto World Values Survey em nosso país, em 1991 e 1997, concluímos que a mencionada associação se verifica no Brasil, entretanto, não como previsto pelos principais pesquisadores vinculados a essa teoria.
\end{abstract}

Palavras-chave: pós-materialismo; valores políticos; democracia; participação.

A s primeiras afirmações acerca da emergência dos chamados vaAlores pós-materialistas datam do final da década de 1970, quando Ronald Inglehart publicou The Silent Revolution (1977). Esse livro tem sido recorrentemente apontado como a obra que inaugura um programa de pesquisas que tem afirmado a ocorrência de uma lenta e contínua alteração nas prioridades valorativas individuais em nível mundial. Quase três décadas de investigações empíricas e teóricas se passaram desde esse impulso inicial e, repetidamente, a tese da mudança de um amplo conjunto de valores humanos em direção a uma postura pós-materialista tem sido testada com base em evidências empíricas coletadas em dezenas de países nos diferentes continentes e regiões do globo. A teoria do desenvolvimento humano, tal como definida por Inglehart e Welzel (2005), é o resultado atual dessa série de investigações.

Os pesquisadores vinculados a essa perspectiva têm afirmado que, a despeito das significativas diferenças culturais existentes entre as nações, essa (re) orientação valorativa estaria ocorrendo especialmente em decorrência do desenvolvimento econômico experimentado a partir da segunda metade do século XX, especialmente pelas sociedades industriais avançadas ou pós-industriais (Inglehart, 1977; 1990; 2001; Inglehart; Welzel, 2005).

No campo político esse fenômeno teria conseqüência positivas sobre os processos de democratização, pois estaria associado à adoção de valores e atitudes congruentes com essa forma de governo (Inglehart; Welzel, 2005). Essas orientações subjetivas, entretanto, 
também seriam acompanhadas de uma postura crítica em relação ao funcionamento das instituições políticas e, sobretudo, pelo questionamento dos mecanismos tradicionais de representação (Inglehart, 1990; 2001; Inglehart; Welzel, 2005). O reflexo dessa atitude crítica seria a redução significativa nas taxas de mobilização política verificadas nas últimas décadas nas sociedades avançadas industrialmente. Esse quadro, entretanto, não seria um sinal de apatia por parte dos públicos dessas nações, pois em paralelo à redução na participação tradicional estaria ocorrendo processo inverso nas chamadas elite-directed political action, ou seja, nas atividades de contestação às instituições e elites estabelecidas (Norris, 2002; Inglehart; Welzel, 2005).

O desejo de tomar parte dos assuntos públicos de uma maneira mais ativa e direta estaria acompanhando, portanto, a mudança pós-materialista. Uma vez superados os limites estritos da sobrevivência física e econômica, os indivíduos estariam se preocupando cada vez mais com questões relacionadas à sua auto-expressão, gerando uma "intervenção cidadã na política” (Inglehart, 2001, p. 221). Evidências empíricas robustas têm sido apresentadas desde o final da década de 1970 para confirmar esses argumentos (Barnes et al., 1979; Inglehart, 1999; Norris, 2002). Em perspectiva mundial os valores pós-materialistas estariam fortemente associados a ações políticas não-convencionais, como manifestações, boicotes ou ocupações, bem como ao interesse por política em geral.

Nesse artigo procuramos verificar se algo parecido ocorre quando a atenção do analista se volta para contextos nacionais particulares, sobretudo quando esses apresentam configurações socioeconômicas significativamente distintas das existentes nas sociedades de industrialização avançada. Tentando contribuir para essa discussão, nos concentramos sobre o caso brasileiro, analisando a existência e a intensidade da associação entre a priorização de objetivos pós-materialistas e um conjunto de valores e atitudes relacionados ao tema da participação política. Ainda que o número de indivíduos pós-materialistas em nosso país seja reduzido, acreditamos que tal questionamento seja relevante, pois a particularidade da cultura política brasileira e nossas baixas taxas de mobilização política podem representar um teste importante para as teses propostas por Inglehart e seus colaboradores em nível mundial.

\section{Questões metodológicas}

Utilizamos nessa pesquisa dados produzidos pelas duas pesquisas conduzidas pelo projeto World Values Surveys (WVS) no Brasil ${ }^{1}$, concluídas em 1991 e $1997^{2}$. O WVS é uma grande investigação sobre mudanças socioculturais e políticas, executada por uma rede global de cientistas sociais com base em surveys aplicados a amostras nacionais representativas de mais de 80 nações espalhadas por todos os continentes. As coletas de dados têm se repetido desde o início da década de $1980 \mathrm{em}$ sucessivas ondas (1980-1984, 1990-1993, 1995-1997, 1999-2002 e 2005) e, na sua última edição concluída, produziu dados representativos para mais de $80 \%$ da população mundial. Como parte de sua terceira onda de investigações, em 1991 o questionário mundial foi aplicado no Brasil a uma amostra representativa de 1782 pessoas. $\mathrm{Na}$ onda subseqüente a amostra nacional foi composta por 1.149 entrevistados.

O índice de materialismo/pós-materialismo desenvolvido por Inglehart (1990) é utilizado como medida de adesão aos valores pós-materialistas em todos os testes e análises que apresentamos. Esse índice é obtido mediante a aplicação de uma bateria composta por 12 itens que representariam os principais objetivos prioritários de qualquer sociedade, a saber: 1) manter a ordem; 2) aumentar a participação dos cidadãos nas decisões importantes; 3) combater o aumento de preços; 4) proteger a liberdade de expressão; 5) manter altas taxas de crescimento econômico; 6) assegurar que o país tenha importantes forças de defesa; 7) dar maior importância à opinião das pessoas sobre os assuntos em seu trabalho e comunidade; 8) fazer das cidades e paisagens mais bonitas; 9) manter a economia estável; 10) progredir em direção a uma sociedade menos impessoal e mais humana; 11) lutar contra a delinqüência; e 12) progredir em direção a uma sociedade onde as idéias são mais importantes que o dinheiro.

Com base nas prioridades selecionadas, os indivíduos são dispostos em uma escala de 6 pontos, na qual 0 (zero) corresponde a uma posição radicalmente materialista e 5 (cinco) a uma postura pós-materialista extremada (Inglehart, 1990).

As variáveis relacionadas aos valores e atitudes participativas e também os procedimentos empregados na construção de alguns índices propostos por nós são apresentados ao longo da exposição e discussão dos resultados ${ }^{3}$.

1 Esses dados estão presentes na base integrada v20060423, que reúne as informações de todas as pesquisas realizadas pelo WVS e também pelo European Values Surveys desde 1980. Essa base integrada está disponível no endereço http://www.worldvaluessurvey. org sob o código xwvsevs_1981_2000_v20060423. Aproveitamos a oportunidade para agradecer a Ronald Inglehart, presidente do WVS, por permitir o acesso aos dados.

2 Infelizmente, a rodada de pesquisas conduzidas por essa organização entre 1999-2002 não incluiu o Brasil. Uma nova pesquisa foi realizada entre 2005 e 2006, porém os dados ainda não estão disponíveis para os pesquisadores independentes.

3 Detalhes e informações técnicas sobre todos os índices e variáveis utilizadas no Apêndice I. 
Em razão dos nossos objetivos, a análise dos dados que apresentamos a seguir busca especialmente verificar a existência e a intensidade da associação entre índices e variáveis. Para tanto, com o emprego do software SPSS 13.0 for Windows, o procedimento estatístico inicialmente utilizado foi o cruzamento entre o índice de materialismo/pós-materialismo mencionado e alguns indicadores disponibilizados pelo WVS sobre os valores e atitudes relativos à participação política.

Para verificar a existência da associação entre as variáveis envolvidas nos cruzamentos optamos pelo coeficiente $\gamma$ (Gamma) de Goodman e Kruskal, útil nos casos em que as variáveis são qualitativas e medidas no nível ordinal, ou seja, com valores agrupados em categorias ordenadas (Bohrnstedt; Knoke, 1982; Barbetta, 2003). É importante salientar que, por se tratar de uma medida de associação simétrica, os valores calculados para $\gamma$ indicam tanto a capacidade de previsão da segunda variável sobre a primeira, quanto o inverso (Bohrnstedt; Knoke, 1982).

Tal coeficiente é obtido através do cálculo da diferença entre o número de concordâncias e discordâncias $\left(n_{c}-n_{d}\right)$ entre os pares de variáveis, dividida pelo número total de pares concordantes ou discordantes $\left(n_{c}-n_{d}\right)$, como segue:

$$
\gamma=\frac{n c-n d}{n c+n d}
$$

Quando só houver concordâncias entre as variáveis o valor de $\gamma$ será 1 e, inversamente, quando só ocorrerem pares discordantes o seu valor será -1 . O valor 0 , por sua vez, indica que o número de concordâncias e discordâncias é idêntico, demonstrando que não existe correlação entre as medidas. Nas tabelas que apresentamos ao longo desse capítulo apresentamos sempre o valor do teste e o seu $p$, que acusará significância estatística sempre que for igual ou menor que 0,05 .

A escolha desse teste também se deve ao fato do mesmo servir como uma estatística de Redução Proporcional de Erro (RPE), útil para identificar quanto o conhecimento de uma primeira variável acrescenta na compreensão de uma segunda (Blalock, 1979; Bohrnstedt; Knoke, 1982).

Em alguns casos relevantes, após verificarmos a ocorrência de associações importantes, nos valemos de modelos de regressão linear simples e múltipla para identificar com maior precisão os efeitos do índice de pós-materialismo sobre algumas das mais importantes variáveis relacionadas aos valores, atitudes e práticas dos entrevistados relacionadas ao tema da participação. Essas técnicas mais complexas, entretanto, não são aplicadas diretamente às questões originalmente disponibilizadas pelo WVS, mas a variáveis escalares construídas com base na combinação de indicadores relacionados a um mesmo tema.

O modelo estatístico-matemático simples de regressão relaciona uma variável $Y$, denominada variável resposta ou dependente, com uma segunda variável $X$, chamada de variável explicativa, independente ou preditora. Como no caso dos testes de correlação e associação, esse tipo de análise toma as observações singulares como pares de dados $(x, y)$ relativos às variáveis envolvidas na equação (Bohrnstedt; Knoke, 1982, Barbetta, 2003). Quando um determinado valor de Y depende parcialmente do valor do seu correspondente $x$ podemos falar de uma relação linear entre essas variáveis, representada pela equação:

$$
Y=\alpha+\beta x
$$

Ao fixarmos valores para $\alpha$ e $\beta$, temos a equação de uma reta assumindo que os valores de $Y$ são exatamente função dos valores de $X$. Entretanto, de maneira geral, observamos que em um conjunto de pares de dados $(x, y)$ os pontos não se colocam exatamente em uma reta, de modo que algum erro de previsão $Y$ deve ser esperado. Dessa forma, é necessário incluir uma medida de erro no modelo. A equação mais adequada, portanto, é a seguinte:

$$
Y=\alpha+\beta x+\varepsilon,
$$

onde o último elemento representa um efeito aleatório causado por fatores que podem impactar $Y$.

Como trabalhamos com mais de uma variável explicativa nas análises apresentadas nos valemos especialmente de modelos de regressão múltipla. Levando em consideração que uma variável dependente geralmente varia em relação a mais de uma medida preditora, esse tipo de procedimento nos permite conhecer a influencia de cada uma dessas sobre $\gamma$. A representação desse modelo mais complexo é a seguinte:

$$
Y=\alpha+\beta_{T} x_{1}+\beta_{z} x_{2}+\ldots+\beta_{k} x_{k}+\varepsilon
$$

Esse procedimento possibilita testar se o relacionamento verificado entre as variáveis envolvidas é realmente válido ou espúrio, sobretudo porque podemos controlar os efeitos da nossa variável independente principal com a inclusão de terceiras variáveis nos modelos. Destacamos desde já que nossa intenção com a aplicação dessa técnica não é construir modelos explicativos robustos acerca das variáveis respostas, mas tão somente identificar a intensidade e a consistência do efeito produzido pelo índice de materialismo/pós-materialismo em cada caso.

\section{Prioridades pós-materialistas e participação}

O nível de interesse dos indivíduos por política tem sido empregado com relativa freqüência nos estudos sobre cultura política como indicador de uma postura participativa (Almond; Verba, 1989; Inglehart, 2001). Em uma perspectiva mundial, dados coletados pelo WVS entre os anos de 1981 e 1990 indicaram uma tendência de elevação no número de entrevistados que se diziam interessados em alguma medida. A verificada redução 
na participação por meio do voto e pelo engajamento em partidos (Norris, 1999), portanto, não tem sido acompanhada pela apatia política dos cidadãos, que se mostram cada vez mais interessados (Inglehart, 2001).

No Brasil, tendência semelhante foi verificada por Moisés (1995) entre os anos de 1989 e 1993, com o percentual de interessados passando de 60,5\% para 68,7\%. Em 2002, segundo o levantamento do ESEB, o percentual acumulado de indivíduos com algum ou muito interesse foi de 60,5 pontos, indicando certa estabilização nessa evolução.

Os dados nacionais produzidos pelo WVS de 1991 e 1997, apesar de utilizarem uma codificação de respostas diferente, indicam um quadro próximo a esse. Tomando a totalidade dos entrevistados temos que em 1991 apenas 36\% declararam não possuir nenhum interesse em política. Na pesquisa posterior esse número se reduz ainda mais, atingindo 31,6 pontos percentuais.

O cruzamento dessa variável com o índice de materialismo/pós-materialismo, como podemos constatar abaixo (Tabela 1), foi favorável à hipótese da associação. Encontramos em relação à amostra de 1991 um coeficiente estatisticamente significativo $(p=0,000)$ e positivo $(\gamma=0,20)$, indicando que elevações no índice que mede as prioridades valorativas são acompanhadas por manifestações de maior interesse. Essa associação ganha maior intensidade na segunda pesquisa $(\gamma=0,28)$, mostrando que com o passar do tempo pós-materialistas tendem a se distinguirem mais dos materialistas.

Para identificar a consistência desses resultados também nos valemos de uma segunda variável diretamente ligada à anterior, obtida pela pergunta: $\mathrm{O}$ Sr.(a) considera importante ou sem importância a política em sua vida?
Consistentemente, as associações verificadas dessa vez foram igualmente significativas e positivas $(0,13$ e 0,22, respectivamente para 1991 e 1997), indicando que pós-materialistas tendem a atribuir mais importância à política.

Outra variável igualmente interessante sobre o tema da participação diz respeito à freqüência com que as pessoas conversam sobre política com seus amigos. Os resultados mundiais apresentados por Inglehart (2001) indicam que dos 21 países pesquisados pelo WVS, 17 manifestaram alguma elevação nesse indicador nas últimas duas décadas. No Brasil situação semelhante pode ser verificada, pois em 1991 55,6\% dos entrevistados optaram pelas alternativas 'às vezes conversam' e 'sempre conversam'. Em 1997 o acumulado nessas duas opções se eleva para $58,2 \%$, indicando uma tendência positiva.

Aqui também verificamos que a adesão aos valores pós-materialistas é acompanhada de uma postura mais ativa. Em ambas as sondagens realizadas, constatamos a ocorrência de coeficientes estatisticamente significativos e positivos. Também encontramos uma tendência de ampliação dessa associação, que de 0,18 em 1991, passa para 0,34 em 1997.

Essas associações nos inspiraram a empreender testes mais complexos que pudessem indicar a intensidade do impacto produzido pela adesão aos valores pós-materialistas sobre os indicadores. Para tanto, construímos um índice somatório de interesse por política reunindo as três medidas acima mencionadas. Essa medida resultou em um escala que vai de 0 a 8 . A média verificada nos dados relativos à pesquisa de 1991 foi de 2,29, com desvio padrão de 2,45. Para

Tabela 1: Pós-Materialismo e Interesse por Política - 1991/1997

\begin{tabular}{|c|c|c|c|c|c|c|c|}
\hline & INTERESSE & & & RIALIS & ÓS-MA & LISMO & \\
\hline & & Materialista & 1 & 2 & 3 & 4 & Pós-materialista \\
\hline & Nenhum & 41,6 & 40,3 & 37,8 & 29,6 & 24,3 & 15,0 \\
\hline न & Pouco & 14,4 & 18,6 & 19,5 & 14,8 & 11,0 & 12,5 \\
\hline & Algum & 32,8 & 32,5 & 33,3 & 38,1 & 35,3 & 35,0 \\
\hline & Muito & 11,2 & 8,6 & 9,4 & 17,6 & 29,4 & 37,5 \\
\hline & Total & 100,0 & 100,0 & 100,0 & 100,0 & 100,0 & 100,0 \\
\hline $\mathrm{N}=1$ & & $0 \quad p=0,000$ & & & & & \\
\hline & INTERESSE & & & RIALIS & ÓS-MA & LISMO & \\
\hline & & Materialista & 1 & 2 & 3 & 4 & Pós-materialista \\
\hline & Nenhum & 53,3 & 39,3 & 33,6 & 25,8 & 17,3 & 9,4 \\
\hline ু & Pouco & 28,3 & 40,9 & 40,7 & 36,3 & 33,7 & 18,8 \\
\hline & Algum & 11,7 & 10,7 & 16,0 & 24,3 & 22,4 & 31,3 \\
\hline & Muito & 6,7 & 9,1 & 9,7 & 13,5 & 26,5 & 40,6 \\
\hline & Total & 100,0 & 100,0 & 100,0 & 100,0 & 100,0 & 100,0 \\
\hline$N=1$ & & & & $\gamma=0$ & $p=0,00$ & & \\
\hline
\end{tabular}

Fonte: European and World Values Surveys four-wave Integrated data file, 1981-2004, v.20060423, 2006. 
1997, a média foi de 3,35 com desvio padrão de 2,28. Em ambas as amostras a distribuição dos dados obteve resultados positivos nos testes de normalidade.

Um primeiro modelo de regressão envolvendo apenas a variável resposta criada e o índice de materialismo/pós-materialismo revelou que o impacto provocado por essa última medida é de 0,18 e 0,28, respectivamente para 1991 e 1997, o que também confirma uma tendência de elevação nesse efeito. Incorporando variáveis de controle ao modelo, com o objetivo de verificar se esse efeito permanece válido, encontramos os resultados que seguem abaixo (Tabela 2). Gostaríamos de salientar que o modelo não possui grande capacidade explicativa sobre a variável dependente, uma vez que explica apenas de 12,8\% e 13,8\% da sua variação. Apesar disso, são úteis para os objetivos propostos em nossa pesquisa.

Tabela 2: Preditores do Interesse por Política

\begin{tabular}{|l|l|l|l|l|}
\hline \multirow{2}{*}{ VARIÁVEL } & \multicolumn{2}{|c|}{1991} & \multicolumn{2}{c|}{1997} \\
\cline { 2 - 5 } & B & BETA & B & BETA \\
\hline $\begin{array}{l}\text { Índice de materialismo/ } \\
\text { pós-materialismo }\end{array}$ & 0,18 & $0,08^{*}$ & 0,43 & $0,21^{*}$ \\
\hline Escolaridade & 1,04 & $0,27^{*}$ & 0,81 & $0,24^{*}$ \\
\hline Sexo (indicadora) & 0,42 & $0,09 *$ & 0,16 & $0,04^{*}$ \\
\hline Renda & 0,34 & $0,11^{*}$ & 0,10 & $0,04^{*} *$ \\
\hline Idade & 0,02 & $0,09 *$ & 0,01 & $0,05^{*} *$ \\
\hline R2 & & 12,8 & & 13,8 \\
\hline
\end{tabular}

Fonte: European and World Values Surveys four-wave

Integrated data file, 1981-2004, v.20060423, 2006.

Nota: * $p \leq 0,001 * * p>0,05$

Levando em consideração os dados de 1991, podemos constatar que a incorporação das variáveis sociodemográficas reduz sensivelmente o impacto provocado pelo índice de materialismo/pós-materialismo, embora ainda permaneça significativo a um nível bastante exigente $(p=0,001)$. A medida referente ao nível de escolaridade dos entrevistados parece ser a que mais contribui para essa redução, o que já era esperado em razão da associação positiva existente entre essa variável e o referido índice, amplamente documentada pela literatura pertinente (Inglehart, 1990; 2001). Os resultados envolvendo os dados de 1997 indicam uma redução bem menor nesse efeito, em virtude da maior associação entre as variáveis fundamentais nessa segunda sondagem. Como podemos ver na tabela acima, o impacto da medida de pós-materialismo foi de 0,21 , o segundo maior do modelo, ficando atrás apenas da escolaridade. É interessante notar que as demais variáveis (sexo, renda e idade) não alcançaram o nível mínimo de significância estatística $(p \leq 0,05)$. Ou seja, na presença da escolaridade e do índice de materialismo/pós-materialismo de 12 itens, essas variáveis não produzem impacto significativo sobre o índice de interesse por política.

Os resultados indicam que o impacto da variável independente continua existindo mesmo quando são inseridas variáveis de controle e, portanto, corroboram a hipótese de que a priorização de objetivos definidos como pós-materialistas é acompanhada no contexto nacional de elevações no grau de interesse individual por política, elemento fundamental do que podemos definir como postura participativa.

Mais diretamente ligado ao nível da ação, o WVS disponibiliza um conjunto de dados relativos à atuação dos entrevistados em diferentes instituições, organizações ou atividades. Como existem diferenças importantes na forma como essas variáveis foram geradas em cada uma das pesquisas conduzidos no Brasil por essa organização, nesse momento dispomos os dados em tabelas distintas. Na pesquisa de 1991, os entrevistados apenas informaram se participavam ou não de um conjunto de instituições. $\mathrm{Na}$ de 1997, ao invés das opções sim ou não, os indivíduos eram levados a escolherem entre as seguintes alternativas: participo ativamente, participo sem atuação e não participo.

Na próxima tabela dispomos os resultados do cruzamento do índice de pós-materialismo e a variável indicadora referente à participação em cada uma das instituições que fizeram parte da investigação. Antes de tratar do relacionamento entre as variáveis, gostaríamos de ressaltar os baixos níveis de participação em todos os tipos de organizações encontrados em 1991. Com exceção das igrejas e organizações religiosas, que contaram com $22 \%$ de participação, entre as demais as taxas não ultrapassaram 10 pontos percentuais. Apenas 10\% afirmaram participar de sociedades beneficentes, $5,4 \%$ de grupos educacionais/artísticos/culturais, $6,7 \%$ de sindicatos, $4,9 \%$ de partidos ou grupos políticos, 7,5\% de grupos locais de discussão, 2,8\% de grupos ecológicos, 4,6\% de organizações profissionais, $8,3 \%$ de grupos esportivos/recreativos e $2,2 \%$ de grupos de mulheres/feministas.

Quanto às associações, verificamos nas tabelas (Tabelas 3 e $4^{4}$ ) que em cinco casos o relacionamento é estatisticamente significativo. Elevações na medida de pós-materialismo estão acompanhadas de maior participação em organizações educacionais, musicais ou artísticas, sindicatos, partidos ou grupos políticos, grupos locais de discussão e associações profissionais. Entre essas, a associação mais intensa ocorreu em relação às associações profissionais, com um coeficiente $\gamma=0,44$. Os coeficientes dos demais cruzamentos ficaram entre 0,19 (sindicatos) e 0,24 (partidos/grupos políticos). 
Tabela 3: Pós-Materialismo e Participação Voluntária - 1991

\begin{tabular}{|c|c|c|c|c|c|c|c|}
\hline \multirow{2}{*}{\multicolumn{2}{|c|}{$\begin{array}{l}\text { ORGANIZAÇÃO/ } \\
\text { ATIVIDADE }\end{array}$}} & \multicolumn{6}{|c|}{ MATERIALISMO/PÓS-MATERIALISMO (\%) } \\
\hline & & \multirow{2}{*}{$\begin{array}{r}\text { Materialista } \\
88,9\end{array}$} & \multirow{2}{*}{$\begin{array}{r}1 \\
92,2\end{array}$} & \multirow{2}{*}{\begin{tabular}{r|}
2 \\
90,5
\end{tabular}} & \multirow{2}{*}{$\begin{array}{r}3 \\
88,7\end{array}$} & \multirow{2}{*}{$\begin{array}{r}4 \\
85,4\end{array}$} & \multirow{2}{*}{$\begin{array}{r}\text { Pós-materialista } \\
90,0\end{array}$} \\
\hline Beneficentes/Caridade & Não & & & & & & \\
\hline & $\operatorname{Sim}$ & 11,1 & 7,8 & 9,5 & 11,3 & 14,6 & 10,0 \\
\hline \multirow[t]{2}{*}{ Religiosas } & Não & 74,6 & 79,8 & 76,8 & 78,2 & 80,3 & 75,0 \\
\hline & $\operatorname{Sim}$ & 25,4 & 20,2 & 23,2 & 21,8 & 19,7 & 25,0 \\
\hline \multirow[t]{2}{*}{ Educacional/artístico/cultural } & Não & 96,0 & 95,3 & 95,5 & 94,9 & 88,3 & 85,0 \\
\hline & Sim & 4,0 & 4,7 & 4,5 & 5,1 & 11,7 & 15,0 \\
\hline \multirow[t]{2}{*}{ Sindicatos } & Não & 95,2 & 94,7 & 93,8 & 92,7 & 86,9 & 92,5 \\
\hline & Sim & 4,8 & 5,3 & 6,2 & 7,3 & 13,1 & 7,5 \\
\hline \multirow[t]{2}{*}{ Partidos/grupos políticos } & Não & 95,2 & 97,5 & 95,1 & 94,3 & 89,8 & 92,5 \\
\hline & $\operatorname{Sim}$ & 4,8 & 2,5 & 4,9 & 5,7 & 10,2 & 7,5 \\
\hline \multirow[t]{2}{*}{ Grupos locais de discussão } & Não & 96,8 & 94,7 & 92,1 & 90,5 & 90,5 & 92,5 \\
\hline & $\operatorname{Sim}$ & 3,2 & 5,3 & 7,9 & 9,5 & 9,5 & 7,5 \\
\hline \multirow[t]{2}{*}{ Ecológicos } & Não & 95,2 & 98,6 & 98,3 & 96,0 & 95,6 & 95,0 \\
\hline & Sim & 4,8 & 1,4 & 1,7 & 4,0 & 4,4 & 5,0 \\
\hline \multirow[t]{2}{*}{ Associações Profissionais } & Não & 99,2 & 98,1 & 96,1 & 93,9 & 89,8 & 85,0 \\
\hline & $\operatorname{Sim}$ & 8 & 1,9 & 3,9 & 6,1 & 10,2 & 15,0 \\
\hline \multirow[t]{2}{*}{ Esportivos/recreativos } & Não & 92,9 & 91,4 & 92,9 & 91,3 & 86,1 & 85,0 \\
\hline & Sim & 7,1 & 8,6 & 7,1 & 8,7 & 13,9 & 15,0 \\
\hline \multirow[t]{2}{*}{ Grupos de Mulheres/ feministas } & Não & 100 & 98,9 & 97,4 & 99,2 & 97,8 & 97,5 \\
\hline & $\mathrm{Sim}$ & 0 & 1,1 & 2,6 & 8 & 2,2 & 2,5 \\
\hline
\end{tabular}

Fonte: European and World Values Surveys four-wave Integrated data file, 1981-2004, v.20060423, 2006.

Tabela 4: Correlações entre Pós-Materialismo

e Participação Voluntária - 1991

\begin{tabular}{|l|l|l|}
\hline ORGANIZAÇÃO/ATIVIDADE & $\gamma$ & $\mathrm{p}$ \\
\hline Beneficentes/Caridade & 0,11 & 0,070 \\
\hline Religiosas & $-0,01$ & 0,787 \\
\hline Educacional/musical/cultural & 0,21 & 0,014 \\
\hline Sindicatos & 0,19 & 0,010 \\
\hline Partidos/grupos políticos & 0,24 & 0,004 \\
\hline Grupos locais de discussão & 0,19 & 0,003 \\
\hline Ecológicos & 0,20 & 0,080 \\
\hline Associações Profissionais & 0,44 & 0,000 \\
\hline Esportivos/recreativos & 0,11 & 0,089 \\
\hline Grupos de Mulheres/feministas & 0,13 & 0,538 \\
\hline
\end{tabular}

Fonte: European and World Values Surveys four-wave Integrated data file, 1981-2004, v.20060423, 2006.

Nota: $\mathrm{N}=1694$ em todas as variáveis.

Vejamos agora como se comportam os dados referentes à segunda pesquisa do WVS, realizada no ano de 1997. Como afirmamos anteriormente, nessa segunda sondagem as perguntas distinguiam dois tipos de participação: ativa e sem atuação. Em comparação com as baixas taxas de participação verificadas em 1991, o panorama aqui é mais favorável, com elevações no percentual dos participantes em todas as instituições, organizações ou atividades.

A participação em organizações religiosas, que em 1991 foi a mais mencionada, aumentou significativamente em 1997. Somando o percentual daqueles que afirmaram participar sem atuação efetiva $(30,7 \%)$ com o daqueles que declaram participar ativamente $(30,8 \%)$, chegamos à impressionante marca de mais de 60 pontos.

As sociedades beneficentes, que contavam com a participação de 10\% dos entrevistados em 1991, passaram nesse segundo momento a contar com $16,2 \%$ de participantes sem atuação e 14,7\% de participantes ativos. Sem considerar essa distinção acerca da qualidade da participação, 30,9\% dos entrevistados afirmaram participar desse tipo de organização.

Quanto às instituições ou organizações voltadas para atividades educacionais, culturais ou artísticas, que em 1991 contavam com apenas 5,4\% de adeptos, verificamos também uma elevação considerável. Somando aqueles que afirmam participarem sem atuação efetiva $(6,8 \%)$ aos participantes ativos $(11,4 \%)$, encontramos um total de $18,2 \%$.

Em 1997, a pesquisa associou sindicatos às demais organizações relacionadas ao trabalho, de modo que alguma elevação seria esperada como conseqüência dessa alteração no instrumento de coleta de dados. Essa mudança, entretanto, não parece ser suficiente para explicar uma elevação de mais de 11 pontos. O percentual acumulado de entrevistados que afirmaram participar ativamente ou não desse tipo de organização alcançou 17,8 pontos.

Em relação aos partidos e grupos políticos encontramos mudança também importante, pois dos 4,9\% de taxa de participação em 1991, passamos nesse segundo momento para o acumulado de $14,2 \%$. 
Aumento igualmente expressivo se deu em relação às organizações de defesa do meio ambiente. Em 1991, apenas $2,8 \%$ dos pesquisados declararam participar desse tipo de organização. Em 1997, esse percentual salta para $14,3 \%$.

Por fim, também encontramos situação mais positiva no que diz respeito às associações profissionais, que contavam na primeira pesquisa com $4,6 \%$ de participantes e na segunda com $16,7 \%$, caracterizando uma elevação de mais de 12 pontos.

No geral, podemos identificar uma tendência de elevação da participação nessas instituições quando comparamos os dados das duas ondas de surveys realizados pelo WVS no território nacional, apesar das diferentes formulações das questões. Resta saber, portanto, se materialistas e pós-materialistas continuam a se distinguirem em termos dessa participação.
Os cruzamentos, coeficientes $\gamma$ e níveis de significância apresentados nas tabelas que seguem (Tabelas 5 e 6) apontam algumas alterações em relação ao quadro anterior. A primeira delas diz respeito à participação em sindicatos, que deixou de estar asssociada à medida de pós-materialismo. Por outro lado, o relacionamento entre essa última variável e a participação em partidos ou grupos políticos sofreu uma ligeira elevação na sua intensidade. A respeito das associações profissionais, apesar da associação continuar significativa, o coeficiente $\gamma$ sofreu uma redução de 0,44 para 0,15 . A participação em clubes esportivos ou recreativos manteve o mesmo coeficiente de associação nessa segunda pesquisa do WVS. Os cruzamentos com as demais variáveis sobre participação continuaram não alcançando o nível de significância estatística mínimo.

Tabela 5: Pós-Materialismo e Participação em Atividade Voluntária - 1997

\begin{tabular}{|c|c|c|c|c|c|c|c|}
\hline \multicolumn{2}{|c|}{ ORGANIZAÇÃO/ATIVIDADE } & \multicolumn{6}{|c|}{ MATERIALISMO/PÓS-MATERIALISMO (\%) } \\
\hline & & \multirow{2}{*}{$\begin{array}{l}\text { Materialista } \\
80,0\end{array}$} & & & & \multirow{2}{*}{\begin{tabular}{|l|}
4 \\
61,2
\end{tabular}} & \multirow{2}{*}{$\begin{array}{l}\text { Pós-materialista } \\
84,4\end{array}$} \\
\hline Beneficentes & Não participa & & & & & & \\
\hline & Participa s/ atuação & 10,0 & 18,7 & 15,7 & 16,7 & 18,4 & 12,5 \\
\hline & Participa ativamente & 10,0 & 17,5 & 13,1 & 13,7 & 20,4 & 3,1 \\
\hline \multirow[t]{3}{*}{ Religiosas } & Não participa & 48,3 & 34,1 & 40,5 & 38,5 & 38,8 & 37,5 \\
\hline & Participa s/ atuação & 25,0 & 31,0 & 29,6 & 33,1 & 24,5 & 37,5 \\
\hline & Participa ativamente & 26,7 & 34,9 & 29,9 & 28,4 & 36,7 & 25,0 \\
\hline \multirow{3}{*}{$\begin{array}{l}\text { Educacional/Musical/ } \\
\text { Cultural }\end{array}$} & Não participa & 88,3 & 85,7 & 86,9 & 79,1 & 67,3 & 53,1 \\
\hline & Participa s/ atuação & 1,7 & 7,1 & 4,6 & 7,2 & 7,1 & 31,3 \\
\hline & Participa ativamente & 10,0 & 7,1 & 8,5 & 13,7 & 25,5 & 15,6 \\
\hline \multirow{3}{*}{$\begin{array}{l}\text { Sindicatos/ } \\
\text { Org. do Trabalho }\end{array}$} & Não participa & 86,7 & 82,1 & 82,6 & 83,3 & 72,4 & 81,3 \\
\hline & Participa s/ atuação & 5,0 & 6,7 & 8,0 & 8,1 & 12,2 & 15,6 \\
\hline & Participa ativamente & 8,3 & 11,1 & 9,4 & 8,7 & 15,3 & 3,1 \\
\hline \multirow{3}{*}{$\begin{array}{l}\text { Partidos/ } \\
\text { grupos políticos }\end{array}$} & Não participa & 96,7 & 88,1 & 88,0 & 84,2 & 73,5 & 71,9 \\
\hline & Participa s/ atuação & 3,3 & 4,8 & 7,1 & 7,5 & 13,3 & 9,4 \\
\hline & Participa ativamente & 0 & 7,1 & 4,8 & 8,4 & 13,3 & 18,8 \\
\hline \multirow[t]{3}{*}{ Ecológicos } & Não participa & 88,3 & 87,7 & 84,6 & 86,0 & 81,6 & 78,1 \\
\hline & Participa s/ atuação & 5,0 & 6,7 & 8,3 & 9,0 & 10,2 & 12,5 \\
\hline & Participa ativamente & 6,7 & 5,6 & 7,1 & 5,1 & 8,2 & 9,4 \\
\hline \multirow{3}{*}{$\begin{array}{l}\text { Associações } \\
\text { Profissionais }\end{array}$} & Não participa & 86,7 & 87,3 & 84,0 & 79,7 & 80,6 & 75,0 \\
\hline & Participa s/ atuação & 1,7 & 4,4 & 6,3 & 8,4 & 6,1 & 12,5 \\
\hline & Participa ativamente & 11,7 & 8,3 & 9,7 & 11,9 & 13,3 & 12,5 \\
\hline \multirow{3}{*}{$\begin{array}{l}\text { Esportivos/ } \\
\text { recreativos }\end{array}$} & Não participa & 86,7 & 76,6 & 73,5 & 74,6 & 64,3 & 59,4 \\
\hline & Participa s/ atuação & 6,7 & 9,5 & 11,1 & 14,3 & 19,4 & 28,1 \\
\hline & Participa ativamente & 6,7 & 13,9 & 15,4 & 11,0 & 16,3 & 12,5 \\
\hline
\end{tabular}

Fonte: European and World Values Surveys four-wave Integrated data file, 1981-2004, v.20060423, 2006. 
Tabela 6: Correlações entre Pós-Materialismo

e Participação Voluntária - 1997

\begin{tabular}{|l|l|l|}
\hline ORGANIZAÇÃO/ATIVIDADE & $\gamma$ & $\mathrm{p}$ \\
\hline Beneficentes & 0,00 & .921 \\
\hline Religiosas & $-0,01$ & .730 \\
\hline Educacional/musical/cultural & 0,28 & .000 \\
\hline Sindicatos & 0,06 & .254 \\
\hline Partidos/grupos políticos & 0,26 & .000 \\
\hline Ecológicas & 0,08 & .163 \\
\hline Associações Profissionais & 0,15 & .007 \\
\hline Esportivos/recreativos & 0,11 & .015 \\
\hline
\end{tabular}

Fonte: European and World Values Surveys four-wave Integrated data file, 1981-2004, v.20060423, 2006. Nota: $\mathrm{N}=1128$ em todas as variáveis.

A principal afirmação que desponta da análise desses dados diz respeito à persistência de associação entre o índice de pós-materialismo e o envolvimento com os partidos políticos. Como já mencionamos, a teoria do desenvolvimento humano defende o argumento de que a priorização de valores pós-materialistas é acompanhada de uma postura crítica em relação às instituições tradicionais de representação política da democracia contemporânea. Assim, essa mudança de valores se refletiria na redução das taxas de participação em eleições, dos níveis de confiança no congresso e instituições correlatas, bem como pela redução na participação em partidos e grupos políticos tradicionais.

No caso brasileiro, entretanto, essa situação não foi constatada. Verificamos que nas duas ondas as elevações no índice de pós-materialismo estão acompanhadas de maior participação nas organizações partidárias.

Outro ponto discordante que emerge dos dados nacionais diz respeito à atividade em grupos ecológicos ou de defesa do meio ambiente. A substituição das preocupações materialistas por objetivos pós-materialistas deveria conduzir, segundo Inglehart (2001), à ênfase na qualidade de vida e na preservação ambiental. Essas novas metas deveriam, em tese, se converter em maior atividade política relacionada a esses assuntos. Essa hipótese, entretanto, não se confirmou entre os brasileiros entrevistados nas pesquisas de 1991 e 1997. Em ambas as amostras não ocorreram associações significativas entre a participação em organizações ligadas ao tema da preservação ambiental e o índice de materialismo/pós-materialismo.

\section{Pós-materialismo e participação não-convencional}

O conjunto dos temas analisados até esse momento diz respeito ao que podemos chamar de participação política convencional. Os valores pós-materialistas, entretanto, estariam mais associados a atividades relacionadas à contestação, como destacam os defensores da teoria do desenvolvimento humano (Inglehart, 2001).

A seguir nos voltamos para modalidades de ação que podem ser definidas como atividades não-convencionais, com o objetivo de verificar se a tendência de associação entre pós-materialismo e atitudes participativas continua a se manifestar.

As pesquisas conduzidas pela WVS incluem uma bateria de perguntas sobre a disposição de participar em quatro formas de ação política dessa natureza. A redação exata dessa bateria é o seguinte:

Vou ler algumas formas de atuação política que as pessoas podem ter e gostaria que me dissesse se realmente já fez alguma dessas coisas, se poderia vir a fazer ou se não faria nunca, de jeito nenhum.

1)Participar de um boicote;

2)Participar de passeatas ou manifestações legalmente autorizadas;

3)Participar de uma greve ilegal;

4) Participar de ocupações de edifícios e fábricas.

$\mathrm{Na}$ realidade, essas questões são réplicas das aplicadas no estudo Political Action (Barnes et al., 1979) e foram elaboradas com o objetivo de verificar se as mudanças culturais intergeracionais e a elevação nos níveis de qualificação estavam impulsionando o surgimento de cidadãos mais ativos (Inglehart, 2001).

Comparando dados de 1981 e 1990 de 21 países, esse autor constatou que tanto em termos de ação afetiva, quanto nas disposições para tal, ocorreu uma tendência de ampliação na adesão a essas práticas em escala mundial (Inglehart, 2001).

Vejamos se essa mesma tendência se manifesta no caso nacional mediante a análise dos dados produzidos pelas duas ondas de investigações conduzidas pelo WVS em nosso país.

Em 1991, 10,3\% dos entrevistados afirmaram já ter participado de boicotes e 36,3\% manifestaram disposição para tal. Em 1997, ocorreu uma retração nesses dois grupos, com $29 \%$ e $6,4 \%$, respectivamente para cada opção. Em relação à participação em passeatas ou manifestações, ao invés de redução verificamos um aumento no número de entrevistados que declararam já ter participado. Em 1991, 39,8\% dos pesquisados informaram que poderiam participar e 18,7\% que já haviam tomado parte. Em 1997, o percentual daqueles que poderiam participar sofreu uma ligeira queda para 38 pontos, entretanto, o percentual daqueles que já haviam participado subiu para 24,8 pontos. Na participação em greves ilegais, verificamos também uma redução, pois em 1991 18,7\% manifestam que poderiam participar e 7,6\% que já haviam participado, ao passo que, em 1997, o primeiro percentual cai para 14,9 pontos e o segundo para 6,5. Por fim, em rela- 
ção às ocupações, constatamos um aumento na participação. Na primeira pesquisa, 12,6\% afirmaram que poderia fazer e $1,9 \%$ que já haviam feito. Na segunda esses percentuais passam para 16,1 e 2,7 pontos, respectivamente.

Em síntese, os dados nacionais indicam uma situação ambígua, na qual algumas práticas não-convencionais tiveram ligeira elevação e outras reduções. Como não dispomos de séries temporais mais longas e consistentes, nos eximimos aqui de análises mais aprofundadas sobre tendências a esse tipo de ação política, até porque nosso maior interesse está na identificação do possível relacionamento entre essas variáveis e a medida de pós-materialismo.

As tabelas que seguem (7 e 8) conduzem à conclusão de que pós-materialistas manifestam maior tendência à participação em ações dessa natureza em ambas as pesquisas. Ainda que ocorra uma redução nos coeficientes de associação entre os dois levantamentos, o relacionamento continua significativo e no sentido previsto pela teoria do desenvolvimento humano. Como não dispomos ainda de ondas subseqüentes de modo a compor séries históricas mais prolongadas, não podemos chegar a uma conclusão nesse momento sobre o significado dessas ligeiras reduções nas medidas de associação.

Tabela 7: Pós-Materialismo e Atividade Política - 1991/1997

\begin{tabular}{|c|c|c|c|c|c|c|c|c|}
\hline \multicolumn{3}{|c|}{ ATIVIDADE } & \multicolumn{6}{|c|}{ MATERIALISMO/PÓS-MATERIALISMO (\%) } \\
\hline & & & Materialista & 1 & 2 & 3 & 4 & Pós-materialista \\
\hline \multirow{12}{*}{ হু } & \multirow{3}{*}{$\begin{array}{l}\text { Boicote } \\
(\mathrm{N}=1640)\end{array}$} & Não, nunca faria & 58,5 & 67,2 & 58,3 & 42,6 & 32,4 & 23,1 \\
\hline & & Poderia fazer & 37,4 & 27,2 & 33,4 & 43,2 & 43,4 & 61,5 \\
\hline & & Já fiz & 4,1 & 5,5 & 8,3 & 14,1 & 24,3 & 15,4 \\
\hline & \multirow{3}{*}{$\begin{array}{l}\text { Passeatas/ Manif. } \\
\text { legais } \\
(\mathrm{N}=1683)\end{array}$} & Não, nunca faria & 48,8 & 53,4 & 42,7 & 31,6 & 24,3 & 12,5 \\
\hline & & Poderia fazer & 36,8 & 37,2 & 40,5 & 44,6 & 41,9 & 37,5 \\
\hline & & Já fiz & 14,4 & 9,5 & 16,8 & 23,7 & 33,8 & 50,0 \\
\hline & \multirow{3}{*}{$\begin{array}{l}\text { Greve ilegal } \\
(\mathrm{N}=1687)\end{array}$} & Não, nunca faria & 80,8 & 80,8 & 76,3 & 68,0 & 55,5 & 57,5 \\
\hline & & Poderia fazer & 16,8 & 12,8 & 17,5 & 21,7 & 29,2 & 35,0 \\
\hline & & Já fiz & 2,4 & 6,4 & 6,2 & 10,3 & 15,3 & 7,5 \\
\hline & \multirow{3}{*}{$\begin{array}{l}\text { Ocupações de } \\
\text { Edif./fábricas } \\
(\mathrm{N}=1664)\end{array}$} & Não, nunca faria & 86,3 & 88,0 & 89,6 & 83,4 & 70,5 & 71,8 \\
\hline & & Poderia fazer & 11,3 & 10,0 & 9,2 & 14,8 & 25,8 & 25,6 \\
\hline & & Já fiz & 2,4 & 2,0 & 1,1 & 1,8 & 3,8 & 2,6 \\
\hline \multirow{2}{*}{\multicolumn{3}{|c|}{ ATIVIDADE }} & \multicolumn{6}{|c|}{ MATERIALISMO/PÓS-MATERIALISMO (\%) } \\
\hline & & & Materialista & 1 & 2 & 3 & 4 & Pós-materialista \\
\hline \multirow{12}{*}{ Бे } & \multirow{3}{*}{$\begin{array}{l}\text { Boicote } \\
(\mathrm{N}=1090)\end{array}$} & Não, nunca faria & 74,1 & 77,1 & 65,6 & 62,0 & 46,9 & 21,9 \\
\hline & & Poderia fazer & 20,4 & 18,6 & 29,7 & 31,9 & 37,5 & 62,5 \\
\hline & & Já fiz & 5,6 & 4,2 & 4,7 & 6,0 & 15,6 & 15,6 \\
\hline & \multirow{3}{*}{$\begin{array}{l}\text { Passeatas/ } \\
\text { Manif. legais }(\mathrm{N}=1124)\end{array}$} & Não, nunca faria & 53,3 & 42,1 & 37,9 & 34,1 & 22,4 & 12,5 \\
\hline & & Poderia fazer & 26,7 & 40,5 & 42,8 & 37,7 & 27,6 & 37,5 \\
\hline & & Já fiz & 20,0 & 17,5 & 19,3 & 28,1 & 50,0 & 50,0 \\
\hline & \multirow{3}{*}{$\begin{array}{l}\text { Greve ilegal } \\
(\mathrm{N}=1120)\end{array}$} & Não, nunca faria & 80,0 & 83,3 & 78,7 & 77,8 & 73,2 & 58,1 \\
\hline & & Poderia fazer & 15,0 & 12,0 & 17,0 & 15,0 & 13,4 & 22,6 \\
\hline & & Já fiz & 5,0 & 4,8 & 4,3 & 7,2 & 13,4 & 19,4 \\
\hline & \multirow{3}{*}{$\begin{array}{l}\text { Ocupações de } \\
\text { Edif./fábricas } \\
(\mathrm{N}=1109)\end{array}$} & Não, nunca faria & 89,8 & 79,6 & 82,9 & 82,8 & 70,1 & 68,8 \\
\hline & & Poderia fazer & 10,2 & 17,1 & 15,1 & 15,1 & 24,7 & 18,8 \\
\hline & & Já fiz & 0 & 3,3 & 2,0 & 2,1 & 5,2 & 12,5 \\
\hline
\end{tabular}

Fonte: European and World Values Surveys four-wave Integrated data file, 1981-2004, v.20060423, 2006. 
Tabela 8: Correlações entre Pós-Materialismo e Atividades Políticas Não-Convencionais - 1991/1997

\begin{tabular}{|c|c|c|c|}
\hline \multirow{5}{*}{ Бু } & ATIVIDADE & $\Gamma$ & $p$ \\
\hline & Boicote & 0,31 & 0,000 \\
\hline & Passeatas/manifestações legais & 0,29 & 0,000 \\
\hline & Greve ilegal & 0,25 & 0,000 \\
\hline & Ocupações de edifícios/fábricas & 0,22 & 0,000 \\
\hline \multirow{5}{*}{ ুু } & ATIVIDADE & $\Gamma$ & $P$ \\
\hline & Boicote & 0,29 & 0,000 \\
\hline & Passeatas/manifestações legais & 0,23 & 0,000 \\
\hline & Greve ilegal & 0,19 & 0,005 \\
\hline & Ocupações de edifícios/fábricas & 0,10 & 0,063 \\
\hline
\end{tabular}

Fonte: European and World Values Surveys four-wave Integrated data file, 1981-2004, v.20060423, 2006.

Assim como procedemos anteriormente, para analisar mais detalhadamente esse tema construímos um índice de participação política não-convencional com base nos quatro itens. Essa nova medida resultou em uma escala que vai de 0 a 8 , com média de 1,84 e desvio padrão de 1,78 para a amostra de 1991 e 1,77 e 1,68 para os dados relativos a 1997.

Definindo essa medida como variável resposta em modelos de regressão simples, nos quais a variável preditora é o índice de materialismo/pós-materialismo, constatamos que apesar da equação ter um poder explicativo reduzido ( $7 \%$ e $4 \%$, respectivamente para 1991 e 1997) os coeficientes Beta foram significativos e na direção esperada. Nos dados referentes a 1991, o impacto produzido pelo índice de pós-materialismo sobre a participação não convencional foi de 0,27 e em 1997 de 0,22.

Com a finalidade de testar a consistência desse efeito, na seqüência apresentamos os resultados encontrados quando inserimos as variáveis de controle já empregadas anteriormente, ou seja, idade, escolaridade, renda e sexo (Tabela 9).

Tabela 9: Preditores da Participação Política Não-Convencional

\begin{tabular}{|l|l|l|l|l|}
\hline \multirow{2}{*}{ VARIÁVEL } & \multicolumn{2}{|c|}{1991} & \multicolumn{2}{c|}{1997} \\
\cline { 2 - 5 } & B & BETA & B & BETA \\
\hline $\begin{array}{l}\text { Índice de materialismo/ } \\
\text { pós-materialismo }\end{array}$ & 0,28 & $0,18^{*}$ & 0,24 & $0,16^{*}$ \\
\hline Escolaridade & 0,54 & $0,19^{*}$ & 0,41 & $0,17^{*}$ \\
\hline Sexo (indicadora) & 0,07 & $0,02^{* *}$ & 0,08 & $0,02^{*}$ \\
\hline Renda & 0,17 & $0,07^{*}$ & 0,10 & $0,05^{*}$ \\
\hline Idade & $-0,02$ & $-0,16^{*}$ & $-0,01$ & $-0,10^{*}$ \\
\hline R2 & & 16,3 & & 9,6 \\
\hline
\end{tabular}

Fonte: European and World Values Surveys four-wave Integrated data file, 1981-2004, v.20060423, 2006.

Nota: * $p \leq 0,001 \quad * * p>0,05$
Como podemos identificar pelos níveis de significância informados na tabela, mesmo após a inclusão das demais variáveis o índice de materialismo/pós-materialismo continua a produzir efeito sobre esse tipo de participação, ocupando a segunda posição em termos de maior impacto produzido. Aqui também a variável sexo não se mostrou importante no modelo. A escolaridade dos indivíduos, fortemente associada à priorização de objetivos pós-materialistas, continua sendo variável importante. É interessante notar os coeficientes negativos na linha correspondente à idade, indicando que elevações nessa medida provocam redução no índice de participação, ou seja, os mais jovens são ligeiramente mais dispostos ou participam mais dessas ações não convencionais.

\section{Conclusão}

O conjunto das análises apresentadas nesse artigo se mostra favorável à validação das hipóteses da teoria do desenvolvimento humano que tendem a associar os chamados valores pós-materialistas a um maior ativismo político. Todavia, algumas particularidades do caso nacional também se tornaram evidentes e merecem ser discutidas.

Entre os entrevistados nas duas ondas do WVS verificamos que pós-materialistas são mais interessados, atribuem maior importância e conversam mais sobre política. Ao compararmos os coeficientes de associação das duas pesquisas notamos até mesmo uma considerável elevação na intensidade do relacionamento em 1997, revelando que com o passar do tempo esse grupo tende a se diferenciar ainda mais. $\mathrm{O}$ destaque aqui vai para a associação entre o índice de pós-materialismo e a freqüência de conversas sobre política que passa de $\gamma=0,18$ para $\gamma=0,34$.

Sobre a participação em instituições ou atividades políticas, como partidos, grupos locais de discussão e 
sindicatos, identificamos maior ocorrência também entre os pós-materialistas. Gostaríamos aqui de destacar que nas duas sondagens analisadas ocorreram associações positivas entre a participação em partidos políticos e o índice de materialismo/pós-materialismo, resultado contrário à hipótese de que esses valores seriam acompanhados pela contestação das modalidades tradicionais de participação política que se dão por meio de instituições tradicionais de representação verticalmente estruturadas.

Apesar dos dados caminharem na direção inversa da prevista pela teoria, acreditamos que devem ser encarados como algo positivo no contexto nacional, marcado por reduzidos níveis de participação política, em grande medida conseqüência da baixa eficácia política subjetiva de nossa população, que leva autores como Carvalho (1999) a definirem o brasileiro como um não-cidadão que sofre conformado com as decisões dos seus senhores soberanos. O simples fato dos pós-materialistas nacionais serem politicamente mais interessados e participativos nos parece algo promissor e favorável ao desenvolvimento democrático, pois indica a possibilidade de superação desse quadro de passividade e sujeição.

Essa interpretação positiva é reforçada pelos dados sobre formas de participação mais autônomas e desafiadoras. Lembramos que os defensores da teoria do desenvolvimento humano afirmam que o abandono das formas tradicionais de atuação seria acompanhado pela ampliação dos níveis de participação em ações políticas não convencionais, como passeatas, greves ilegais, boicotes e ocupações. Na maioria dos casos, com exceção da participação em ocupações na pesquisa de 1997, constatamos que o engajamento nesse tipo de atividade está relacionado com o índice de 12 itens. Dessa forma, os indivíduos classificados como pós-materialistas seriam mais participativos tanto nas modalidades tradicionais, quanto nas contestatórias o que torna problemático o quadro explicativo proposto por Inglehart
(2001; 2005) e exige algum esforço de interpretação.

É preciso, primeiramente, salientar que a tendência a maior participação convencional não pode ser interpretada como indício de postura conservadora ou favorável a relações políticas hierárquicas, pois o referido grupo também se destaca na participação contestatória. Por outro lado, ao aderiram às duas modalidades de atuação esses mesmos indivíduos negam uma postura radical de superação das instituições clássicas da democracia. Essa situação nos leva a pensar em uma postura mista que apesar de buscar alternativas mais independentes de manifestação dos anseios por autoexpressão não abandona os mecanismos tradicionais de participação e representação. Apenas pesquisas futuras poderão indicar se essa particular combinação irá manter-se ao longo do tempo, mas por hora somos levadas a entendê-la como benéfica ao processo democrático nacional. Tendo em vista que nossa jovem democracia ainda luta para consolidar-se efetivamente e o sistema partidário ainda mostra fragilidades relevantes, essa postura mista pode ser algo positivo, uma vez que pressiona o sistema político com demandas mais genuinamente participativas e desafiadoras sem reivindicar a derrubada dos mecanismos de representação formalmente estabelecidos.

Para finalizar, gostaríamos de esclarecer que ao salientarmos as especificidades nacionais e propormos possíveis interpretações não temos a intenção de denunciar possíveis fragilidades da teoria do desenvolvimento, mas apenas alertar para a necessidade da realização de pesquisas em nível nacional para testar as suas afirmações, produzidas geralmente mediante a análise agregada de dados de diferentes países. Assim, buscamos tão somente demonstrar que as particularidades da cultura política de unidades nacionais específicas não podem ser desconsideradas, pois podem influenciar de maneira significativa os caminhos pelos quais a chamada síndrome de valores pós-materialistas impacta o processo democrático em cada contexto.

\section{Referências}

ALMOND, Gabriel; VERBA, Sidney. The Civic Culture: political attitudes and democracy in five nations. New York: Sage, 1989.

BARBETTA, Pedro A. Estatística aplicada às ciências sociais.5. ed. Florianópolis, Ed. da UFSC, 2003.

BARNES, Samuel et al. Political Action: mass participation in five western democracies. Beverly Hills: Sage Publications, 1979.

BLALOCK, Hubert M. Social Statistics. New York: McGraw-Hill, 1979.
BOHRNSTEDT, George G.; KNOKE, David. Statistics for Social Data Analysis. New York: Peacock, 1982.

CARVALHO, J. M. O motivo endêmico no imaginário social brasileiro. In.: PANDOLFI, D. C. et al. (Orgs.). Cidadania, justiça e violência. Rio de Janeiro: Fundação Getúlio Vargas, 1999.

INGLEHART, Ronald. The Silent Revolution. Princeton, Princeton University Press, 1977. . Culture shift in advanced industrial society. Princeton, Princeton University Press, 1990. 
Postmodernization, authority, and democracy. In: NORRIS, P. (Org.). Democratic Phoenix: political activism worldwide. Cambridge: Cambridge University Press, 1999.

Modernización y posmodernización: el cambio cultural, económico y político en 43 sociedades. Madrid: Centro de Investigaciones Sociológicas/Siglo Veintiuno, 2001.

; WELZEL, Christian. Modernization, cultural change, and democracy: the human development sequence. New
York: Cambridge University Press, 2005.

MOISÉS, José A. Os Brasileiros e a Democracia: bases sóciopolíticas da legitimidade democrática. São Paulo: Ática, 1995.

NORRIS, Pippa. Critical Citizens: global support for democratic government. Oxford: Oxford University Press, 1999.

Democratic Phoenix: political activism worldwide. Cambridge: Cambridge University Press, 2002.

\title{
Postmaterialism and Political Participation in Brazil
}

\begin{abstract}
Defenders of the human development theory have affirmed that a change process in individuals' value priorities in direction to a postmaterialistic posture has been happening in world scale in the last decades. One of the main components of that change might be the aspiration for self-expression that, on its turn, would engender demands for mechanisms that make the active and autonomous participation on the citizens in politics possible. In the present article, we analyzed the validity of that thesis in the Brazilian context, in which the pertinent literature has indicated the existence of a political culture full of authoritarian elements and not very favorable to the establishment of participative practices. We deal, therefore, with testing the hypothesis of the association of post materialistic syndrome and a group of values and attitudes related to the theme of participation in the national population. Using the data produced by the two researches accomplished by the World Values Survey Project in our country in 1991 and 1997, we conclude that the mentioned association is verified in Brazil, though not as foreseen by main researchers connected to this theory.
\end{abstract}

Key words: postmaterialism; political values; democracy; participation.

Data de recebimento do artigo: 08-07-2008

Data de aprovação do artigo: 25-10-2008 


\section{Apêndice I}

Abaixo são listadas as variáveis utilizadas nas análises, seus números de identificação na base integrada do World Values Survey, suas respectivas codificações originais e as recodificações realizadas.

\begin{tabular}{|c|c|c|c|}
\hline Variável & $\mathrm{N}^{\circ}$. WVS & Codificação & Recodificação \\
\hline $\begin{array}{l}\text { Índice de materialismo/pós-materialismo de } 12 \text { itens } \\
\text { (1991/1997) }\end{array}$ & Y001 & $\begin{array}{l}0=\text { materialista } / 1=1 / 2=2 / 3=3 / 4=4 / 5=\text { pó } \\
s \text {-materialista }\end{array}$ & Sem recodificação \\
\hline Sexo (1991/1997) & X001 & $1=$ masculino $/ 2=$ feminino & $0=$ feminino $/ 1=$ masculino \\
\hline Idade (1991/1997) & $\mathrm{X} 003 \mathrm{r}$ & $\begin{array}{l}1=15-24 / 2=25-34 / 3=35-44 / 4=45- \\
54 / 5=55-64 / 6=65 \text { e mais }\end{array}$ & Sem recodificação \\
\hline Renda (1991/1997) & X047r & 1=baixa $/ 2=$ média $/ 3=$ alta & Sem recodificação \\
\hline Escolaridade (1991/1997) & $\mathrm{X} 025 \mathrm{r}$ & 1=baixa $/ 2=$ média $/ 3=$ alta & Sem recodificação \\
\hline Interesse por política (1991/1997) & E023 & $1=$ muito $/ 2=$ algum $/ 3=$ pouco $/ 4=$ nenhum & $\begin{array}{l}0=\text { nenhum } / 1=\text { pouco } / \\
2=\text { algum } / 3=\text { muito }\end{array}$ \\
\hline Importância da política (1991/1997) & A004 & $\begin{array}{l}1=\text { muito importante } / 2=\text { importante } / \\
3=\text { pouco importante } / 4=\text { sem importância }\end{array}$ & $\begin{array}{l}0=\text { sem importância } / 1=\text { pouco } \\
\text { importante } / 2=\text { importante/ } \\
3=\text { muito importante }\end{array}$ \\
\hline Conversas sobre política (1991/1997) & A062 & $\begin{array}{l}1=\text { sempre conversam } / 2=\text { às vezes } \\
\text { conversam } / 3=\text { não, nunca conversam }\end{array}$ & $\begin{array}{l}0=\text { não, nunca conversam } / 1=\text { às ve- } \\
\text { zes conversam } / 2=\text { sempre conversam }\end{array}$ \\
\hline Participação em sociedade beneficente (1991) & A064 & $0=$ não participa $/ 1=$ participa & Sem recodificação \\
\hline Participação em organização religiosa (1991) & A065 & $0=$ não participa $/ 1=$ participa & Sem recodificação \\
\hline $\begin{array}{l}\text { Participação em organização educacional/artística/cultural } \\
\text { (1991) }\end{array}$ & A066 & $0=$ não participa $/ 1=$ participa & Sem recodificação \\
\hline Participação em sindicatos (1991) & A067 & $0=$ não participa $/ 1=$ participa & Sem recodificação \\
\hline Participação em partidos/grupos políticos (1991) & A068 & $0=$ não participa $/ 1=$ participa & Sem recodificação \\
\hline Participação em grupos locais de discussão (1991) & A069 & $0=$ não participa $/ 1=$ participa & Sem recodificação \\
\hline $\begin{array}{l}\text { Participação em grupos ou movimentos de conservação } \\
\text { amb/ecológicos }\end{array}$ & $\mathrm{A} 071 \mathrm{~b}$ & $0=$ não participa $/ 1=$ participa & Sem recodificação \\
\hline Participação em associações profissionais (1991) & A072 & $0=$ não participa $/ 1=$ participa & Sem recodificação \\
\hline Participação em organizações esportivas/recreativas (1991) & A074 & $0=$ não participa $/ 1=$ participa & Sem recodificação \\
\hline Participação em grupos de mulheres/feministas (1991) & A075 & $0=$ não participa $/ 1=$ participa & Sem recodificação \\
\hline Participação em instituição de caridade (1997) & A105 & $\begin{array}{l}0=\text { não participa } / 1=\text { participa sem } \\
\text { atuação } / 2=\text { participa ativamente }\end{array}$ & Sem recodificação \\
\hline Participação em igreja ou organização religiosa (1997) & A098 & $\begin{array}{l}0=\text { não participa } / 1=\text { participa sem } \\
\text { atuação } / 2=\text { participa ativamente }\end{array}$ & Sem recodificação \\
\hline $\begin{array}{l}\text { Participação em organização artística, cultural ou educacio- } \\
\text { nal (1997) }\end{array}$ & A100 & $\begin{array}{l}0=\text { não participa } / 1=\text { participa sem } \\
\text { atuação } / 2=\text { participa ativamente }\end{array}$ & Sem recodificação \\
\hline $\begin{array}{l}\text { Participação em sindicatos ou organizações do trabalho } \\
\text { (1997) }\end{array}$ & A101 & $\begin{array}{l}0=\text { não participa } / 1=\text { participa sem } \\
\text { atuação } / 2=\text { participa ativamente }\end{array}$ & Sem recodificação \\
\hline Participação em partidos ou grupos políticos (1997) & A102 & $\begin{array}{l}0=\text { não participa } / 1=\text { participa sem } \\
\text { atuação } / 2=\text { participa ativamente }\end{array}$ & Sem recodificação \\
\hline $\begin{array}{l}\text { Participação em organização de defesa do meio ambiente } \\
\text { (1997) }\end{array}$ & A103 & $\begin{array}{l}0=\text { não participa } / 1=\text { participa sem } \\
\text { atuação } / 2=\text { participa ativamente }\end{array}$ & Sem recodificação \\
\hline Participação em associações profissionais (1997) & A104 & $\begin{array}{l}0=\text { não participa } / 1=\text { participa sem } \\
\text { atuação } / 2=\text { participa ativamente }\end{array}$ & Sem recodificação \\
\hline Participação em organização esportiva ou recreativa (1997) & A099 & $\begin{array}{l}0=\text { não participa } / 1=\text { participa sem } \\
\text { atuação } / 2=\text { participa ativamente }\end{array}$ & Sem recodificação \\
\hline Participação em boicotes (1991/1997) & A026 & 1=já fiz/2=poderia fazer/3=não faria nunca & $\begin{array}{l}0=\text { =Não faria nunca/ } 1=\text { =Poderia } \\
\text { fazer/2=Já fiz }\end{array}$ \\
\hline $\begin{array}{l}\text { Participação em passeatas ou manifestações legais } \\
\text { (1991/1997) }\end{array}$ & E027 & 1=já fiz/2=poderia fazer/3=não faria nunca & $\begin{array}{l}\text { 0=Não faria nunca } / 1=\text { =Poderia } \\
\text { fazer/2=Já fiz }\end{array}$ \\
\hline Participação em greve ilegal (1991/1997) & E028 & 1=já fiz/2=poderia fazer/3=não faria nunca & $\begin{array}{l}0=\text { =Não faria nunca } / 1=\text { =Poderia } \\
\text { fazer/2=Já fiz }\end{array}$ \\
\hline $\begin{array}{l}\text { Participação em ocupações de edifícios ou fábricas } \\
\text { (1991/1997) }\end{array}$ & E029 & 1=já fiz/2=poderia fazer/3=não faria nunca & $\begin{array}{l}0=\text { =Não faria nunca } / 1=\text { =Poderia } \\
\text { fazer } / 2=J a ́ \text { fiz }\end{array}$ \\
\hline
\end{tabular}

